\title{
A social equity analysis of the U.S. public transportation system based on job accessibility
}

\section{Armin Jeddi Yeganeh \\ Virginia Tech \\ yeganeh@vt.edu}

Annie R. Pearce

Virginia Tech

apearce@vt.edu

\author{
Ralph P. Hall \\ Virginia Tech \\ rphall@vt.edu \\ Steve Hankey \\ Virginia Tech \\ apearce@vt.edu
}

\begin{abstract}
Access to quality public transportation is critical for employment, especially for low-income and minority populations. This study contributes to previous work on equity analyses of the U.S. public transportation system by including the 45 largest Metropolitan Statistical Areas (MSAs) in a single analysis. Year-2014 Census demographic data were combined with an existing 2014 dataset of transit job accessibility. Then, transit equality and justice indicators were developed and a regression analysis was performed to explore trends in transit job accessibility by race and income. The findings suggest that within individual MSAs, low-income populations and minorities have the highest transit job accessibility. However, the overall transit ridership is low, and in certain MSAs with high transit job accessibility both high and low income populations have high access levels but middle income populations do not. Within individual MSAs, on average, accessibility differences by income are greater than accessibility differences by race. The relative importance of race versus income for injustice increases with MSA size. In upper mid-size and large MSAs, differences by race increase. Also, the differences by race are greater among low-income populations. Accessibility-related equality and justice indicators are only one of many issues that comprise the wider discussion of equity.
\end{abstract}

Keywords: Social sustainability, transit equity, the Gini Index, equality, justice

\section{Article history:}

Received: January 11, 2018

Received in revised form:

March 3, 2018

Accepted: August 27, 2018

Available online: November 13, 2018

Copyright 2018 Armin Jeddi Yeganeh, Ralph P. Hall, Annie R. Pearce \& Steve Hankey http://dx.doi.org/10.5198/jtlu.2018.1370

ISSN: 1938-7849 | Licensed under the Creative Commons Attribution - Noncommercial License 4.0

The Journal of Transport and Land Use is the official journal of the World Society for Transport and Land Use (WSTLUR) and is published and sponsored by the University of Minnesota Center for Transportation Studies. 


\section{Introduction}

To provide the public with high levels of mobility, planners of the early twentieth century focused on increasing the speed of travel through private automobile ownership. However, investment in roads has been unable to keep pace with growth in vehicle travel, environmental consequences have made the goal less achievable (Handy, 2002), and funding for aging road infrastructure has been insufficient for maintenance (ASCE, 2017). Additionally, automobiles are expensive for low-income populations (Shen, 1998) limiting the social and economic participation of people without a private vehicle.

In recent years, communities have shifted from encouraging mobility to encouraging accessibility with a specific focus on sustainable transport (e.g., walking, cycling, public transport) (Bertolini, Le Clercq, \& Kapoen, 2005; Mihyeon \& Amekudzi, 2005). Improving accessibility is an increasingly important indicator and a common goal in many transportation plans in U.S. cities (El-Geneidy \& Levinson, 2006; USDOT, 2012; USDOT Office of the Secretary, 2012). Public transport may play a key role in improving accessibility for populations that cannot afford private vehicles.

The USDOT requires Metropolitan Planning Organizations (MPOs) to satisfy Title VI of the Civil Rights Act of 1964 as well as other federal statutes and regional equity policy priorities (Sanchez, Stolz, \& Ma, 2003). The U.S. Federal Transit Administration publishes the discriminatory actions prohibited under Title VI regulations (i.e., nobody should be excluded or subjected to discrimination when receiving federal financial assistance based on race, color, or national origin). Despite the existing regulations, people of color and underserved communities have been segregated, displaced, or discriminated against as a result of the negative impacts of transportation planning and urban renewal programs in the U.S. (Kain, 1968; Rose \& Mohl, 2012; Sanchez, et al., 2003). Environmental justice studies (starting in the 1960s-1980s) that assess exposure to environmental risks (e.g., polluting industries, vehicle traffic) have been extensively reported (Clark, Millet, \& Marshall, 2014). Transport modeling and cost-benefit analyses have primarily focused on adverse environmental impacts (Martens, 2006) which are easier to measure than social impacts (Manaugh, Badami, \& El-Geneidy, 2015). Although public transit is a particularly important system for underserved communities, the social impacts of transportation decisions are less clearly defined (Karner, 2016).

Transit accessibility indicators measure the impact of land-use and transit infrastructure decisions on an individual's opportunity to participate in activities at various geographic locations (Geurs \& van Wee, 2004). Transit equity indicators assess the impact of land-use and transit developments on populations with the greatest potential need for public transportation. Consequently, simultaneously assessing accessibility and equity indicators may help inform policy and design decisions aimed at increasing transit equity (Bocarejo \& Oviedo, 2012). Relationships between transit use and Socio-Economic Status (SES) have been documented in studies of single U.S. cities (e.g., Grengs, 2010; Hu, 2015; Shen, 1998; Welch \& Mishra, 2013). No studies have explored this relationship across multiple cities; thus, limiting the ability to assess overarching trends across cities. We aim to address this gap by presenting a cross-sectional analysis of the current status of equity in transit access in U.S. cities. We present results from the 45 largest Metropolitan Statistical Areas (MSAs) to assess whether the trends identified in cityspecific analyses are consistent at a national scale. We assess transit equality and justice using the following two indicators for each city: (1) the Gini index of cumulative accessibility and (2) the difference in accessibility between low-income non-Whites and high-income Whites. We also perform a regression analysis using our cross-sectional dataset to explore differences in accessibility by race and income. While our analyses offer insight into trends among cities, accessibility-related equity indicators are only one of many issues that comprise the wider discussion of equity (van Wee \& Geurs, 2011). 


\section{$2 \quad$ Literature review}

\subsection{Indicators of accessibility}

Accessibility measures the ease of reaching destinations or activities (i.e., combining spatial aspects of land use and the transportation network) rather than impedance across the network (El-Geneidy \& Levinson, 2006). Accessibility has been defined in various ways, e.g., the potential for interaction with opportunities, the ease of reaching any destination using a specific transportation system, or the overall benefits provided by a given transportation system (Bertolini et al., 2005; Bhat et al., 2000; Bocarejo \& Oviedo, 2012). The concept of accessibility was introduced in the 1950s by Hansen (1959) as "the potential for interaction" and Weibull (1980) who considered accessibility as a property of the configuration of opportunities for spatial interaction (Geurs, Krizek, \& Reggiani, 2012). A more precise definition of accessibility, proposed by Geurs \& van Wee (2004), is "the extent to which land-use and transport systems enable (groups of) individuals to reach activities or destinations by means of a (combination of) transport mode(s).” Also, Geurs \& van Wee (2004) classified existing indicators into four groups: infrastructure-based, location-based, person-based, and utility-based.

The literature describing the measurement of accessibility is relatively rich and significant differences exist among measurement methods (Linneker \& Spence, 1992). Typically, accessibility indicators focus on specific components of access (e.g., employment) or specific transportation systems (e.g., public transportation) (Geurs \& van Wee, 2004); the indicators typically include both an impedance factor (e.g., time, cost, etc.) and an attractiveness factor of the destination (Geurs et al., 2012; Handy, 2002). A widely used group of accessibility indicators measure the number of potential opportunities that can be reached within a predetermined travel time or distance from a given location. However, an implicit assumption in many accessibility indicators is that available demand for opportunities is uniformly distributed across space or that available opportunities have no capacity limitation (Shen 1998); thus, in reality, accessibility by its definition is unevenly distributed. Furthermore, previous studies show that (for measures of job accessibility) inclusion of occupational matching (i.e., whether residents in close proximity to job opportunities have the required skills or education) has a strong effect on indicator performance (Fan, Guthrie, \& Levinson, 2010; Geurs \& Ritsema van Eck, 2003).

In general, the literature suggests that accessibility indicators often address different components of transportation systems and that no single indicator captures all important factors (e.g., level of education, occupation type, job market) in addition to the spatial attributes of the transportation network and destinations. While limitations exist for each method, recent advances have allowed for generating some indicators on a national scale (e.g., Owen \& Levinson, 2014) allowing for assessment of trends at a national (rather than city) scale. For a detailed comparison, and guidance on how to evaluate accessibility indicators see Geurs \& van Wee (2004).

\subsection{Equality, justice, and accessibility}

Transit and land use planning decisions often have significant equity impacts. Bullard (1994) defined three basic types of equity based on the extent disadvantaged communities are exposed to regulatory, geographic, and social discrimination. The concepts of equality and justice commonly create a basis for equity analysis in the literature (e.g., Clark, et al., 2014). Transit equality refers to the even distribution of costs and benefits of transportation services across the population within a geography (e.g., MSA or county) regardless of income, social class, need, or ability. In this sense, equity cannot be seen as the spatially uniform distribution of benefits in a geographical region since that approach ignores varying population densities or the varying needs of all residents (Foth, Manaugh, \& El-Geneidy, 2013). Transit 
justice refers to the prioritization of the population with the greatest potential need for subsidized services with respect to income and social class or need and ability (Welch, 2013), often implemented in order to remediate the prevalent disproportionality of accessibility.

Prioritization of equality or justice could result in different policy goals depending on the context. Also, philosophical differences exist in how to implement findings in practice. For example, the RawIsian principles of justice would suggest that the least advantaged groups should receive the greatest benefit while the Utilitarian view of Liberalism would support the idea of the greatest benefit to the most people (Pereira, Banister, Schwanen, \& Wessel, 2017; van Wee \& Geurs, 2011). Martens (2012) suggests that applying accessibility as a transport good cannot be strongly shaped by the principles that govern the distribution of income. Rather, accessibility should be guided by a distinct transport policy that may include components of equality and justice. For further reading on the philosophical and legal basis of transportation equity see Bullard, 1994; Litman, 2002; Martens, 2016; Martens, Golub, \& Robinson, 2012; MTC, 2009; Sanchez, et al, 2003.

When selecting a single (or a combination of) indicator(s) to assess transit policy decisions, different impacts on different population groups should be considered. Manaugh et al. (2015) suggest that the application of social equity indicators should specify the impacts and improve the inclusion of disadvantaged groups. Previous studies have used indicators such as the Gini or Theil index (Ramjerdi, 2006) to operationalize transit equality and differences by SES groups (e.g., income level, vehicle ownership, language barriers, etc.) (Delbosc \& Currie, 2011; Sanchez, et al., 2003) to operationalize transit justice. Karner \& Niemeier (2013) suggest that the use of a combination of indicators in one index to capture more than a single SES variable does not always accurately reflect a group's travel behavior since composite groups may not congregate spatially; thus, these indicators may reflect some combination of the group's travel behavior combined with other residents of the areal unit used for analysis. For guidance on transit equity as a component of social exclusion see Bocarejo \& Oviedo, 2012; Burchardt, Le Grand, \& Piachaud, 1999; Chen, \& Akar, 2016; Currie \& Delbosc, 2010; Kenyon, Lyons, \& Rafferty, 2002; van Wee \& Geurs, 2011; Witter, 2010.

Since metropolitan areas are increasingly investing in public transportation systems, it is critical to address both obstacles and opportunities that planning for equity is likely to face when intersecting with politics (Bullard \& Johnson, 1997; Bullard, Johnson, \& Torres, 2004; Grengs, 2002; Whitt, 2014). Transit investments can be evaluated from many perspectives, e.g., user costs and benefits (e.g., accessibility, fares), service quality (e.g., congestion), external impacts (e.g., pollution, noise), economic impacts (e.g., economic opportunities, employment), and regulation and enforcement (e.g., traffic regulation) (Litman, 2016). Making balanced decisions toward the successful realization of social equity goals has proven challenging (Behrsin \& Benner, 2017; Walker, 2008) and requires a clear understanding of local political ecology to navigate potentially conflicting goals; for example, whether transit investments should reduce the overall number of private cars or serve vulnerable populations who have few transport options (Grengs, 2010). Martens (2006) argues that existing transit modeling and cost-benefit evaluation practices are demand-based, which exaggerate the benefits of automobile-oriented investments. He suggests that more robust indicators of transit accessibility that include both spatial (e.g., number of jobs) and personal (e.g., physical ability, financial budgets) characteristics rather than travel time alone would more accurately measure the benefits of transit.

\subsection{Key findings from city-specific analyses of transit equality and justice}

MPOs typically assess whether a target group receives the same benefit or burden as the total population to evaluate equity of transit accessibility (Karner \& Niemeier, 2013; Manaugh et al., 2015). Changes in accessibility to desired (work and non-work) destinations or differences between transit and car accessibility levels are often evaluated (Golub \& Martens, 2014); some studies use multi-criteria decision mak- 
ing and simulation models to forecast changes in travel behavior (Bills, Sall, \& Walker, 2012). Metrics originally developed to assess income inequality (e.g., Gini Index, Theil Index) are currently the most widely used indicators to assess transit equity (Franklin, 2005).

Many studies have used the Gini Index to measure transit equality and found that the indicator is useful for representing the overall degree of inequality due to its scale- and demand-independence (Bertolaccini \& Lownes, 2013); however, it is sensitive to boundary characteristics (Delbosc \& Currie, 2011; Feng, \& Zhang, 2014; Ramjerdi, 2006; Zhicai, Qingyu, Zhongning, \& Hongfei, 2008). Researchers (e.g., Franklin, 2005) have proposed more mathematically complex indicators to address the limitations of the Gini Index; however, increased complexity may make such indicators difficult for practitioners to apply. In addition to the use of more conventional methods, Karner \& Niemeier (2013) recommend sensitivity analyses using activity-based models, different areal units, and composite indicators since variation in target populations and the definition of equity may affect the analysis.

Transit justice suggests that greater allocation of resources should be provided for more economically, socially, or physically disadvantaged groups or geographic areas. There is no single standard indicator of transit justice (Welch \& Mishra, 2013) since equity standards vary (Bills \& Walker, 2017). However, a common approach is to compare gains between SES strata (e.g., income deciles) both within transit mode and among all modes (Bureau \& Glachant, 2011) to help identify existing access gaps within or between the study areas (Litman, 2002). The target population groups are typically defined based on either single SES variables or composite indices (Foth, et al. 2013).

Previous city-specific analyses of transit equality and justice report mixed findings depending on the context of the study. Kain (1968) introduced the spatial mismatch theory; subsequently, many cityspecific analyses have shown associations between increases in racial minority population and decreases in job accessibility and transit service (Dumas, 2015; Golub, Marcantonio, \& Sanchez, 2013; Grengs, 2001; Hickey, Lu, \& Reddy, 2010; Wells \& Thill, 2012). However, other results have been mixed; for example, some studies found shorter commute times for Black workers as compared to Whites (Zax, 1990), while others found shorter commute times for Whites from predominantly minority areas (Taylor \& Ong, 1995). Some studies report that low-income and racial minorities have higher transit job accessibility than medium and high-income groups and Whites (Chen \& Akar, 2016; Grengs, 2012); similarly, dramatic variations in job accessibility exist depending on residential location (Blumenberg \& Ong, 2001) and vehicle ownership (Grengs, 2012; Shen, 1998). Karner \& Golub (2015) demonstrated the critical role of the data source (e.g., census data vs. ridership data) in determining the outcome of a service equity analysis. In general, results from city-specific analyses suggest variation in the degree to which disadvantaged groups are associated with levels of job accessibility by transit (Hess, 2005). The mixed results suggest the need for a multi-city investigation of the social equity of transit accessibility (which is the goal of this study) to assess variation in trends across cities.

\section{Methodology}

Our analysis utilizes two publicly available datasets that measure job accessibility by transit and U.S. Census-based SES. We develop two analyses to explore equality and justice trends across 45 U.S. cities and compare to previous studies that focus on a single city. First, we provide descriptive trends among cities using an equality indicator (Gini Index) and a justice indicator (differences among SES groups). Second, we develop regression models to compare associations by race and income groups.

\subsection{Accessibility and demographic data}

We obtained a 2014 transit job accessibility dataset from the Access Across America project managed by the Center for Transportation Studies at the University of Minnesota. In this project, a cumulative 
opportunity indicator of accessibility was used to identify the number of jobs that are available within a 30-minute threshold. The transit travel times were evaluated from each Census Block centroid based on a detailed pedestrian network and published transit schedule data. The researchers used Open Trip Planner (OTP), an open-source multimodal trip planning and analysis tool, to calculate the transit travel time. Travel time calculations were repeated for departure times between 7:00-9:00 am at one-minute intervals. The accessibility values for all departure times were averaged to indicate the number of jobs that are accessible between 7:00-9:00 am from each Census Block. For further reading on the accessibility indicator see Owen \& Levinson (2014).

We obtained demographic data from the U.S. Census Bureau's 2014 ACS 5-year estimate dataset for all 45 MSAs for which the accessibility data were available. Since the Census Block level data do not contain household income data, Block Group (BG) was used as the spatial unit of analysis. Accessibility data were averaged to reflect population-weighted mean job accessibility (MJA) at the BG level according to Equation (1):

$$
\bar{A}=\frac{\sum_{i=1}^{n}\left(A_{i} \times P_{i}\right)}{\sum_{i=1}^{n}\left(P_{i}\right)}
$$

where $\bar{A}$ is the population-weighted mean job accessibility (MJA) in the target area (i.e, county or MSA). $\mathrm{A}_{i}$ and $\mathrm{P}_{i}$ are the average job accessibility and the corresponding population living in the BGs. Only the population in the labor force (18-64 years old) were included in the demographic data since the accessibility dataset only reported access to jobs. Selected SES variables used for further analysis were primarily income and race (auto-use and English speaking ability were assessed in sensitivity analyses). The resulting BGs $(\mathrm{n}=103,834)$ have a total population of $158,477,134$ that consists of $54.0 \%$ White, $14.1 \%$ Black, $7.4 \%$ Asian, and $21.7 \%$ Hispanic populations. The mean BG population is 1,526 . The MJA is 37,005 for Whites, 47,413 for Blacks, 74,604 for Asians, and 47,030 for Hispanics. The accessibility data combines frequency, speed, distance, capacity, required transfers, and employment density of the land use served by the corresponding transit service.

\subsection{Employed equity indicators}

MJA, equality, and justice metrics were calculated by county and MSA. MJA was calculated for each BG separately by income and race. Since our study aims to assess variation in trends among cities as reported in the single city studies, we chose to use consistent metrics to those reported previously. Based on the review of city-specific studies, we used the Gini Index as a measure of equality since it was the most commonly cited indicator. The Gini Index assesses whether the distribution of an indicator (e.g., accessibility) is distributed equally among the population (Ceriani \& Verme, 2012) with 0 representing perfect equality and 1 representing inequality. In this study, the Gini Index represents the evenness of the distribution of job access (MJA) across the MSA or county populations (living in BGs) regardless of income, social class, need, or ability. The Gini Index, as discussed above, may have advantages and disadvantages for integration into policy objectives; for example, perfect equity of transit services among the population may not be preferable if the goal is to provide service to underserved populations. Nonetheless, the Gini Index provides a scale- and demand-independent means for assessing to what extent MJA is close to equality.

We used the difference in MJA (by applying equation 1 to each group) between low-income nonWhites (LINW) and high-income Whites (HIW) as the primary indicator of justice. LINW is defined as non-Whites in the lowest median household income decile; HIW is defined as Whites in the highest median household income decile. LINW and HIW are reported as a ratio to each MSA's mean MJA to 
account for differences in overall accessibility among cities. Then, using these ratios, we calculated differences between groups with a higher positive difference between LINW and HIW indicating relatively higher job accessibility for LINW and higher justice. Table 1 provides a summary of the dataset. Autouse and English as the spoken language are reported in Table S1.

Table 1: Population and job accessibility among BGs aggregated by race and median household income

\begin{tabular}{|c|c|c|c|c|c|c|c|c|c|c|c|c|}
\hline 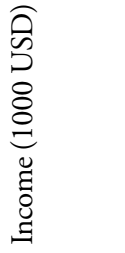 & 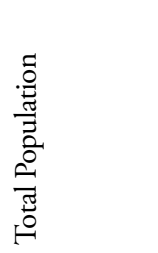 & $\underset{\Sigma}{\mathbb{\Sigma}}$ & $\begin{array}{l}\frac{\mathscr{H}}{2} \\
\frac{3}{8} \\
0\end{array}$ & 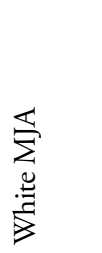 & $\begin{array}{l}\frac{y}{\tilde{y}} \\
\frac{\pi}{00} \\
0\end{array}$ & 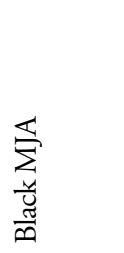 & $\begin{array}{l}\frac{\pi}{0} \\
\frac{0}{2} \\
0 \\
0\end{array}$ & 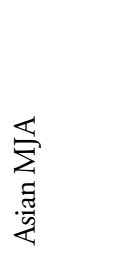 & 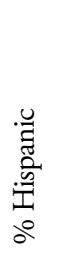 & 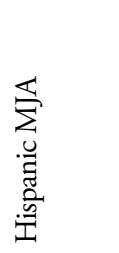 & $\begin{array}{l}\dot{\vec{E}} \\
\dot{0} \\
\dot{0} \\
0\end{array}$ & 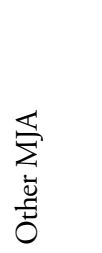 \\
\hline $0-25$ & $8,844,643$ & 91,314 & 21.5 & 69,083 & 39.6 & 76,389 & 4.3 & 259,358 & 31.9 & 102,858 & 2.7 & 80,568 \\
\hline $25-50$ & $46,304,184$ & 42,895 & 38.2 & 28,678 & 20.8 & 47,557 & 5.3 & 98,550 & 33.0 & 47,492 & 2.7 & 42,257 \\
\hline $50-75$ & $46,851,571$ & 30,640 & 57.0 & 25,507 & 12.1 & 32,992 & 7.0 & 57,517 & 21.0 & 33,873 & 2.9 & 33,071 \\
\hline $75-100$ & $29,477,404$ & 35,779 & 66.8 & 33,466 & 7.8 & 38,480 & 8.6 & 53,898 & 14.0 & 32,871 & 2.8 & 42,209 \\
\hline $100-125$ & $15,515,068$ & 49,681 & 71.6 & 49,500 & 5.8 & 39,160 & 10.0 & 57,602 & 9.9 & 47,056 & 2.7 & 57,106 \\
\hline $125-150$ & $6,527,371$ & 68,181 & 73.3 & 67,773 & 4.2 & 56,543 & 12.2 & 73,666 & 7.4 & 67,603 & 2.9 & 73,984 \\
\hline $150-175$ & $2,873,074$ & 87,013 & 73.8 & 87,077 & 3.4 & 81,043 & 13.4 & 88,686 & 6.7 & 81,194 & 2.8 & 98,275 \\
\hline $175-200$ & $1,148,942$ & 82,821 & 75.9 & 81,304 & 2.4 & 56,051 & 13.3 & 83,053 & 5.6 & 105,966 & 2.7 & 99,717 \\
\hline $200-225$ & 587,858 & 93,153 & 77.3 & 93,395 & 2.1 & 106,267 & 11.8 & 82,881 & 6.1 & 107,734 & 2.7 & 88,066 \\
\hline $225-250$ & 347,019 & 58,279 & 79.6 & 60,754 & 1.6 & 53,282 & 10.6 & 34,937 & 5.5 & 74,342 & 2.6 & 46,454 \\
\hline
\end{tabular}

In addition to the descriptive indicator analyses described above, we also used multivariate regression to assess trends in MJA when accounting for multiple explanatory factors (e.g., race and income). A normality test on job accessibility data indicated the need for log-transformation for regression analysis. Using a simple linear regression model (and BG as the spatial unit of analysis), we examined the effects of income and race as the core variables of interest (Table S2-S9). BGs were aggregated by MSA and income interval ( $\$ 2,500$ income bins) to reduce error and uncertainty in the ACS income data estimates. We performed the regression analysis grouping by two MSA-level variables: (1) land area and (2) worker density (the number of resident workers per $\mathrm{km}^{2}$ of the MSA). The regression analyses were performed for each race category in each MSA group yielding 16 models each for the area-based and density-based grouping (Table S2-S17). We assigned MSA-specific dummy variables to control for between-MSA differences in overall accessibility. We also included the percentage of the White population, and the percentage of the population with limited English speaking ability as a sensitivity analysis in supplementary models (Table S10-S17).

\section{$4 \quad$ Results}

\subsection{Descriptive analysis of transit equality and justice among MSAs}

Table 2 represents individual MSA information including MJA, Gini Index, job accessibility of highincome Whites (HIW) and low-income non-Whites (LINW), worker density, and the mean percentage of transit use as the method of commute. The supporting information (Table S20) includes county-level information. In Table 2, HIW and LINW are given as the ratio to the MSA's mean job accessibility. As expected, job accessibility in each metro area is both highly correlated with transit ridership (Pearson 
correlation coefficient $[\mathrm{P}]=0.94)$ and with worker density $(\mathrm{P}=0.73)$. However, there is not a significant correlation between job accessibility and the Gini Index (indicator of equality) or the difference between LINW and HIW (indicator of justice) (Table S18).

In general, LINW is more than HIW among MSAs. Certain MSAs such as New York, Washington, DC, Houston, and Chicago have high overall job accessibility and very little difference between LINW and HIW. Among all MSAs, Louisville, Cincinnati, Nashville, Minneapolis, and Baltimore have the highest level of LINW as compared to HIW. In Minneapolis and Baltimore, low-income populations have the highest MJA, and transit ridership is relatively high. In general, job accessibility is negatively correlated to income decile (Table S19). However, certain MSAs (e.g., New York, Washington, D.C., Houston, and Chicago) do not follow this trend. In these MSAs, high-income deciles have very high job accessibility suggesting policy recommendations may differ by MSA. Job accessibility aggregated by income decile in individual MSAs are included in the supporting information (Table S19). Figure 1 shows the nation-wide spatial patterns of the Gini Index and LINW-HIW. Figure 2 shows the same patterns in the top eight MSAs with the highest job accessibility. The equality and justice metrics are neither correlated with each other, nor with SES variables, such as race and income (Table S18). At the county level, equality metrics (the Gini Index) ranged from 0.10 (Le Sueur County, MN) to 0.87 (Clermont County, OH). Justice metrics (LINW-HIW) ranged from -1.88 (Hudson County, NJ) to 13.61 (Clermont County, OH). See the Supporting Information (Table S20) for the equality and justice metrics by county.

Table 2: Metropolitan areas ranked by the population-weighted mean job accessibility

\begin{tabular}{|c|c|c|c|c|c|c|c|c|}
\hline & $\underset{\Sigma}{\mathbb{\Sigma}}$ & 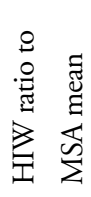 & 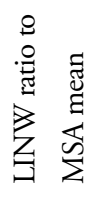 & 疍 & 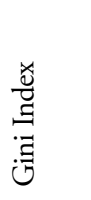 & 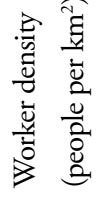 & 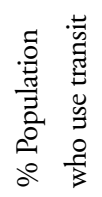 & 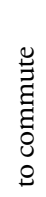 \\
\hline New York, NY & 202,130 & 1.51 & 1.61 & 0.10 & 0.804 & 468 & 31.9 & \\
\hline Washington, D.C. & 72,599 & 0.95 & 1.17 & 0.22 & 0.767 & 183 & 14.6 & \\
\hline San Francisco, CA & 60,427 & 0.35 & 2.28 & 1.93 & 0.736 & 297 & 15.5 & \\
\hline Los Angeles, CA & 46,908 & 0.33 & 2.76 & 2.43 & 0.646 & 417 & 5.9 & \\
\hline Chicago, IL & 46,499 & 1.03 & 1.45 & 0.43 & 0.776 & 223 & 13.0 & \\
\hline Philadelphia, PA & 43,117 & 0.12 & 4.16 & 4.04 & 0.761 & 226 & 13.2 & \\
\hline Boston, MA & 41,549 & 0.48 & 3.55 & 3.07 & 0.787 & 377 & 13.3 & \\
\hline Seattle, WA & 24,105 & 0.66 & 2.19 & 1.53 & 0.794 & 101 & 8.3 & \\
\hline Milwaukee, WI & 22,738 & 0.15 & 3.52 & 3.37 & 0.628 & 197 & 5.3 & \\
\hline Minneapolis, MN & 20,779 & 0.26 & 5.46 & 5.21 & 0.729 & 106 & 5.3 & \\
\hline Denver, CO & 19,945 & 0.39 & 1.92 & 1.53 & 0.683 & 55 & 4.6 & \\
\hline Portland, OR & 18,033 & 0.74 & 1.93 & 1.19 & 0.686 & 57 & 6.2 & \\
\hline San Jose, CA & 17,167 & 0.51 & 1.62 & 1.11 & 0.495 & 114 & 3.3 & \\
\hline Baltimore, MD & 16,338 & 0.13 & 5.28 & 5.14 & 0.786 & 184 & 9.4 & \\
\hline Miami, FL & 15,589 & 0.52 & 2.73 & 2.21 & 0.661 & 167 & 4.3 & \\
\hline Houston, TX & 14,161 & 1.72 & 2.00 & 0.29 & 0.773 & 111 & 2.7 & \\
\hline Salt Lake, UT & 13,851 & 0.33 & 2.67 & 2.34 & 0.578 & 21 & 2.9 & \\
\hline Pittsburgh, PA & 13,011 & 0.56 & 5.42 & 4.86 & 0.810 & 79 & 6.9 & \\
\hline San Diego, CA & 12,204 & 0.28 & 2.36 & 2.08 & 0.626 & 116 & 3.2 & \\
\hline Buffalo, NY & 12,202 & 0.25 & 3.31 & 3.06 & 0.614 & 129 & 4.8 & \\
\hline Hartford, CT & 12,068 & 0.20 & 5.28 & 5.07 & 0.735 & 143 & 3.7 & \\
\hline Providence, RI & 11,003 & 0.36 & 3.80 & 3.44 & 0.648 & 201 & 3.1 & \\
\hline
\end{tabular}




\begin{tabular}{|c|c|c|c|c|c|c|c|}
\hline Dallas, TX & 10,628 & 0.63 & 1.93 & 1.30 & 0.724 & 124 & 1.7 \\
\hline Sacramento, CA & 10,616 & 0.68 & 2.77 & 2.08 & 0.726 & 64 & 2.8 \\
\hline Phoenix, AZ & 10,207 & 0.37 & 2.95 & 2.58 & 0.680 & 44 & 2.5 \\
\hline Cleveland, $\mathrm{OH}$ & 9,961 & 0.24 & 4.94 & 4.70 & 0.668 & 179 & 5.3 \\
\hline San Antonio, TX & 9,851 & 0.40 & 2.95 & 2.55 & 0.691 & 46 & 3.0 \\
\hline Columbus, $\mathrm{OH}$ & 9,838 & 0.29 & 3.75 & 3.45 & 0.726 & 81 & 2.7 \\
\hline New Orleans, LA & 8,747 & 0.63 & 3.05 & 2.42 & 0.663 & 59 & 4.7 \\
\hline Las Vegas, NV & 8,611 & 0.28 & 2.36 & 2.08 & 0.633 & 39 & 4.8 \\
\hline Louisville, KY & 7,628 & 0.24 & 6.78 & 6.53 & 0.737 & 54 & 2.8 \\
\hline Austin, TX & 7,510 & 0.16 & 1.67 & 1.51 & 0.784 & 72 & 2.5 \\
\hline Detroit, MI & 7,430 & 0.46 & 3.11 & 2.64 & 0.563 & 170 & 3.1 \\
\hline Cincinnati, $\mathrm{OH}$ & 7,291 & 0.15 & 5.90 & 5.75 & 0.751 & 84 & 2.8 \\
\hline Atlanta, GA & 7,210 & 0.88 & 2.92 & 2.04 & 0.835 & 101 & 4.1 \\
\hline Kansas, MO & 6,974 & 0.54 & 4.01 & 3.47 & 0.717 & 47 & 1.9 \\
\hline Indianapolis, IN & 6,918 & 0.21 & 5.07 & 4.86 & 0.714 & 81 & 1.6 \\
\hline Charlotte, NC & 6,644 & 1.44 & 3.72 & 2.28 & 0.816 & 97 & 2.4 \\
\hline Tampa, FL & 6,580 & 0.64 & 3.27 & 2.63 & 0.662 & 170 & 1.8 \\
\hline Raleigh, NC & 5,476 & 0.63 & 4.55 & 3.92 & 0.811 & 95 & 1.2 \\
\hline Nashville, TN & 5,272 & 0.36 & 5.68 & 5.32 & 0.816 & 48 & 1.6 \\
\hline Virginia Beach, VA & 5,022 & 0.32 & 2.66 & 2.34 & 0.608 & 101 & 2.2 \\
\hline Orlando, FL & 4,854 & 0.69 & 2.79 & 2.09 & 0.721 & 103 & 2.0 \\
\hline Riverside, CA & 4,405 & 0.32 & 2.10 & 1.78 & 0.593 & 21 & 1.7 \\
\hline Birmingham, AL & 3,285 & 0.67 & 4.05 & 3.38 & 0.773 & 33 & 1.2 \\
\hline & & & & & & & \\
\hline
\end{tabular}

Figure 1: MS- level Gini Index (left) and LINW-HIW (right) for transit job accessibility 


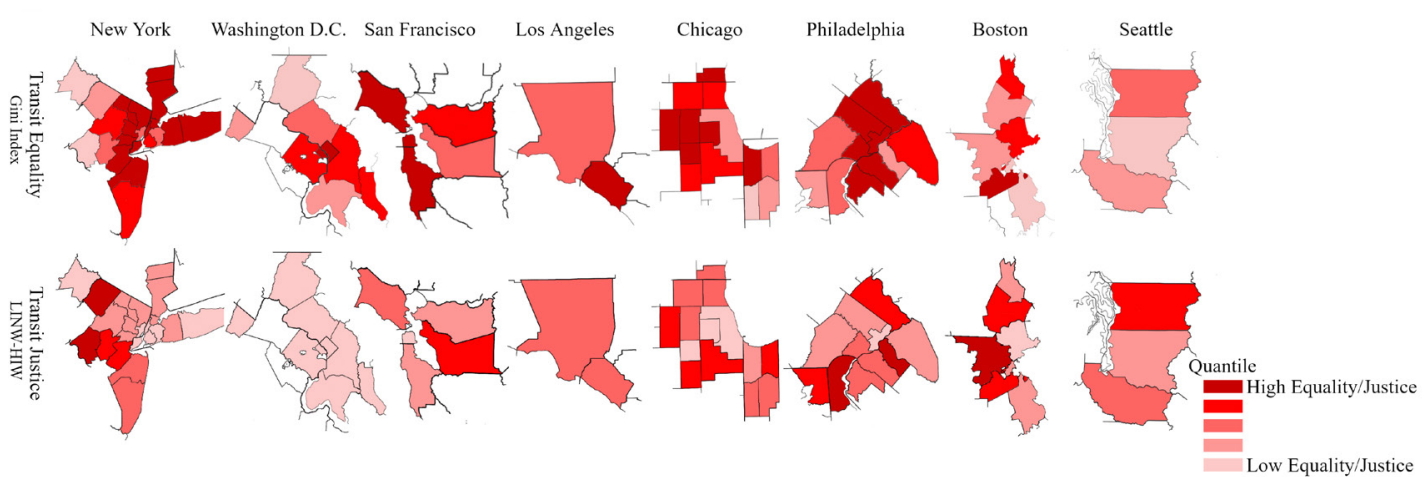

Figure 2: County-level Gini Index (top row) and LINW-HIW (bottom row) for transit job accessibility in the top eight MSAs with the highest job accessibility

\subsection{Regression analyses of transit accessibility based on MSA size, density, and SES variables}

All regression models show a significant relationship between MJA and income. Supplementary regression models (Table S10-S17) show there is a significant negative correlation between MJA and ability to speak English or the percentage of White workers. Figure 3 and Figure 4 present model-based predictions of MJA as a function of the average median household income for the four largest race-ethnicity groups (Whites, Blacks, Asians, Hispanics) by MSA size (land area) and MSA density (the number of workers living in each $\mathrm{km}^{2}$ area). The regression models reveal an inverse relationship between MJA and the average median household income (model p-value $<0.01$ ). Across household income groups, job accessibility is often highest for Asians and lowest for Whites.

Accessibility values shown in Figure 3 are modeled using simple linear regression. All models are statistically significant at $\mathrm{p}<0.01$. Average difference $(A D)$ values shown are for interquartile range incomes $(\$ 42.5 \mathrm{k}, \$ 82.5 \mathrm{k}$ ) and for race-ethnicity groups with the highest and lowest job accessibility for that panel. Within individual MSAs, on average, accessibility differences by income are greater than accessibility differences by race (after controlling for income). The relative importance of race versus income for justice increases with MSA size. Also, the differences by race are greater among low-income populations. In upper mid-size and large MSAs, differences by race increase. In large MSAs, accessibility differences by the percentage of White workers are significant controlling for race and income (Table S10-S17). In small and mid-size MSAs, accessibility differences by the percentage of workers with limited English speaking ability are significant controlling for race and income (Table S10-S17). Figure 4 shows the relative importance of race versus income for justice increases with MSA density. In low-density MSAs, differences by race increase among the low-income populations. In upper medium density and high-density MSAs, disparities by race increase among all income groups. Also, the relative importance of race versus income for justice increases with MSA density. Based on these observations, Asians have the highest transit access, often followed by Blacks, Hispanics, and Whites. 


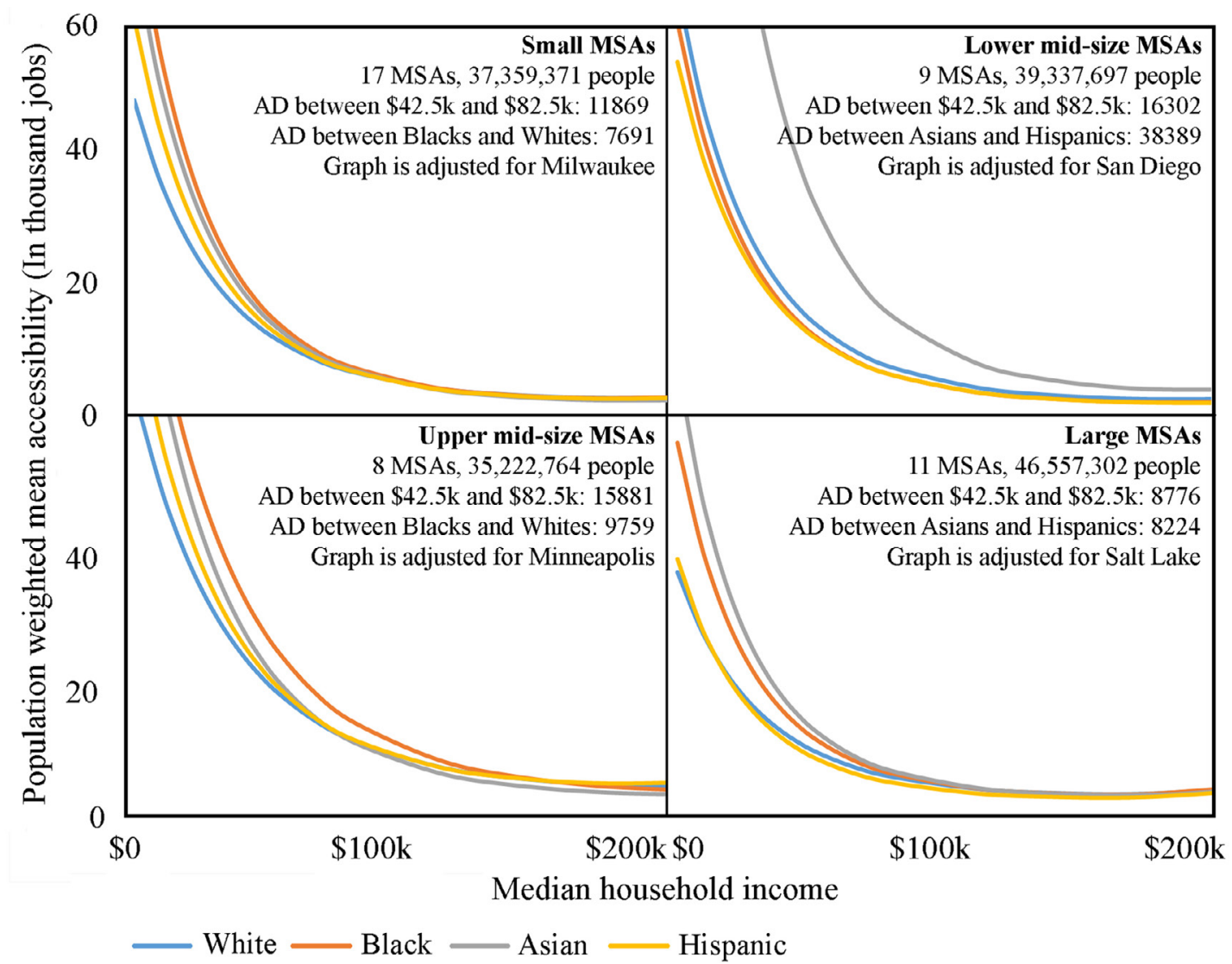

Figure 3: Within-MSA MJA by median household income, race, and MSA area. 


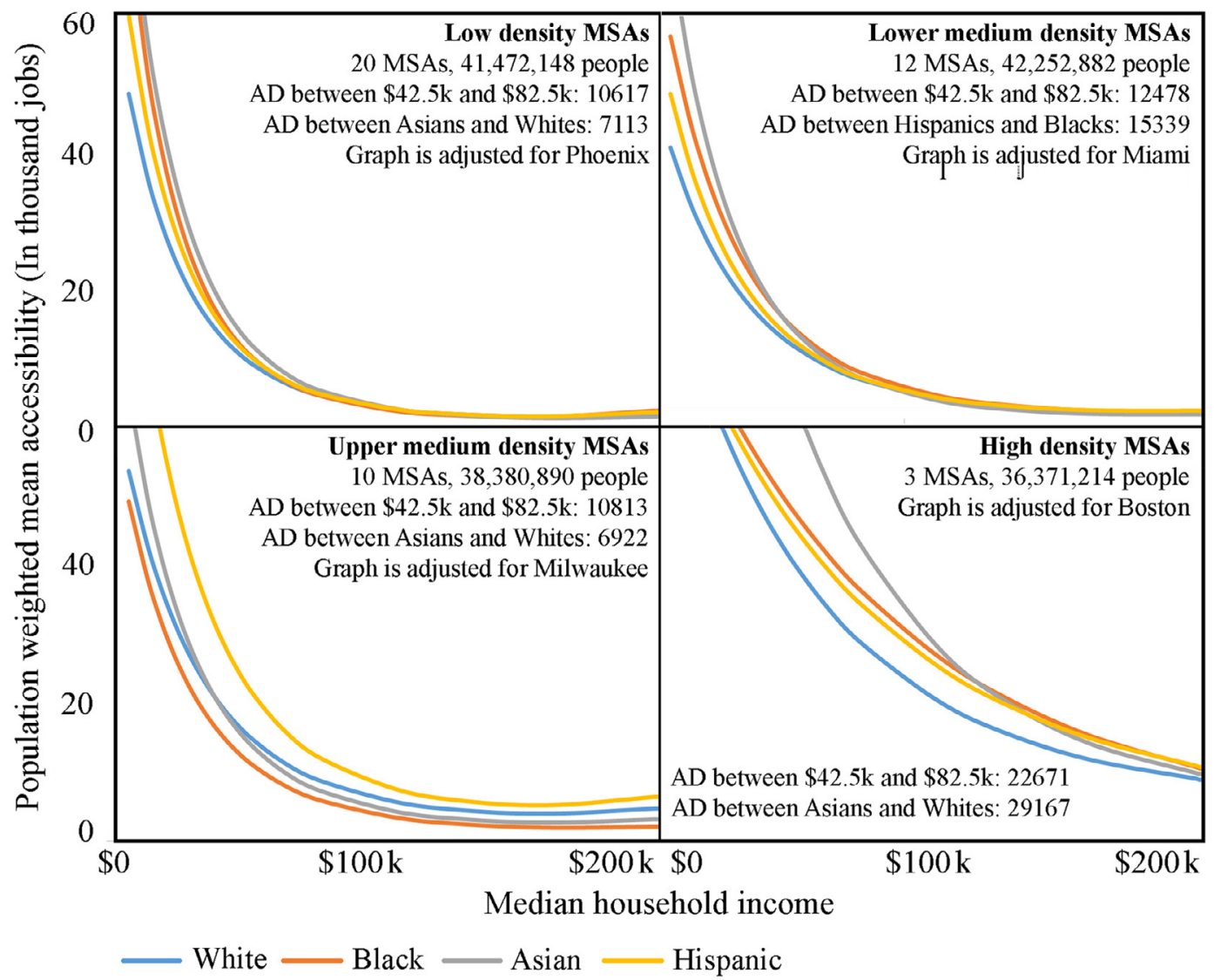

Figure 4: Within-MSA MJA by median household income, race, and MSA density.

\section{$5 \quad$ Discussion and conclusion}

\subsection{Strengths and limitations}

Accessibility is an important indicator of benefits from transportation plans and investments (Golub, \& Martens, 2014). Previous research on job accessibility and social equity of public transportation often include one or few small areas, cities, or regions. A contribution of this research is the inclusion of the 45 largest MSAs in a single analysis using the most detailed evaluation to date of access to jobs by transit (Owen \& Levinson, 2014).

There are limitations with both the transit data and Census demographic data since neither cover within BG variations, nor do they provide more than a limited number of SES and transit-related variables. For example, the cumulative opportunity indicator of accessibility, which is used in this study, counts the number of jobs that are available only within a 30-minute threshold regardless of other important factors, such as occupational matching. In fact, if residents of an area are close to many job opportunities, but do not have the required modal connections, flexible transit schedules, and skills or education, they still have low access to employment. This study covers the largest MSAs, which are home to the majority of the nation's racial and ethnic groups and immigrants. In addition, these areas include a high concentration of rental housing. Thus, the conclusions made by this study may not reflect the reality in small MSAs and their counties. 
We acknowledge limitations associated with the choice of equality and justice indicators. No single indicator can represent all aspects of these concepts. For example, the Gini Index may provide unrealistic or undesirable goals for providing perfect equality in transit systems. Public transit is effective when linking high densities of potential users to high densities of potential destinations. Thus, it is difficult for operators to provide exactly equal service across a region. Furthermore, the Gini Index is sensitive to boundary selection (see, e.g., Bertolaccini \& Lownes, 2013; Feng \& Zhang, 2014). Thus, several measures with analyses of other transportation modes should be applied along with the Gini Index to compare and contrast the equity implications of different policies. For example, justice indicators (such as the indicator described here) may be appropriate when providing improved access to underserved communities is desired.

\subsection{Key findings and comparison to previous work}

Except in certain MSAs, we find that access to jobs by the use of public transportation is generally higher for low-income and non-White populations. This finding is in agreement with previous research that highlights the attractiveness of public transportation for low-income and minority populations (e.g., Glaeser, Kahn, \& Rappaport, 2008; Sanchez, et al., 2003) and with research at the MSA level (e.g., Chen, \& Akar, 2016). In large MSAs, such as New York, Washington, DC, Chicago, and Houston, high-income deciles have relatively higher job accessibility levels (which is consistent with Hickey, et al., 2010). The existing studies on income and distance from the CBD support this finding by showing that in these specific MSAs the BGs closest to the city center are often among the wealthiest in the metropolitan area and in close proximity to low-income BGs. Most other MSAs follow a different pattern in which the high-income populations, who are mostly White and can afford a personal vehicle, tend to move towards suburbs and have lower job accessibility by transit (Merlin, 2016). Our analysis demonstrated that income is an important variable; however, it is useful to include race, the percentage of White populations living in the area, and the percentage with limited English speaking abilities in transit equity analyses to assess job accessibility patterns among BGs. In some MSAs (Table S9-S16), within low-income populations, there is a disproportionate difference in accessibility levels between those who live in predominantly White communities and those who live in predominantly non-White communities (which is consistent with Taylor \& Ong, 1995). Also, those with limited English speaking ability seem to have significantly lower transit job accessibility in certain MSAs (Table S9-S16).

This study explored one aspect of transportation infrastructure - benefits associated with access to jobs by transit. Any infrastructure investment should assess both benefits and burdens of a project. For example, previous work on air pollution (e.g., Clark, et al., 2014) suggests low-income non-White populations experience higher exposure to air pollution. Thus, transit service benefits and the resulting burdens (e.g., air pollution, noise, change in housing value, etc.) should be considered simultaneously in any broad equity analysis. One important consideration in this regard, which is also evident in the literature on equity, is whether disproportionate siting comes first or disproportionate groups of minorities re-locate due to the low cost of housing (see, e.g. Pastor, Sadd, \& Hipp, 2001).

\subsection{Implications for future research}

Improved accessibility indicators should include modal, temporal, and occupational matching factors. Using both Census data and ridership data, future multi-city analyses could address the access gap between where underserved communities reside and where relevant jobs are located. More work is needed to assess intermodal accessibility, for example, trends of job accessibility by car and transit. In general, tracking trends in equality and justice indicators over time would create a basis for an adaptive response 
that may help to prevent inequitable developments and increase agency responsiveness to the public.

The literature on transit equity suggests that limitations in measuring job accessibility also apply to the operationalization of transit equity indicators in practice. Social equity is difficult to evaluate in detail because of the limitations of our ability to develop robust indicators and measure various impacts. These limitations are evident in the U.S. Census Bureau's 2014 ACS 5-year estimate data as well as many of the publicly available accessibility indicators. Geographical and procedural equity analysis is not within the scope of the current research. Nevertheless, there is a need to optimize the existing indicators that measure how finance and prioritization of transit projects contribute to better access to opportunities, particularly, for underserved communities (Bocarejo \& Oviedo, 2012). Despite increases in public transit investment, usage continues to decline as a percentage of urban travel. Cost of travel is an important factor and ignoring transit fares may result in an overestimation of job accessibility (El-Geneidy, et al., 2016). Access to retail, school, health, and recreational facilities for different population groups should be investigated along with other equity metrics. For further guidance on equity analysis of transit investment see Karner (2016); Manaugh, et al. (2015); MTC (2009); Walker (2008).

\section{Acknowledgements}

We thank Thomas Sanchez at Virginia Tech, Lara Clark at University of Washington, and two anonymous reviewers who provided insight and expertise that greatly assisted the research. We thank Carl and Jane Belt at The Belt Group. 


\section{References}

ASCE (2017). 2017 Infrastructure report card. Retrieved from www.infrastructurereportcard.org

Bertolaccini, K., \& Lownes, N. (2013). Effects of scale and boundary selection in assessing equity of transit supply distribution. Transportation Research Record: Journal of the Transportation Research Board, (2350), 58-64.

Bertolini, L., Le Clercq, F., \& Kapoen, L. (2005). Sustainable accessibility: a conceptual framework to integrate transport and land use plan-making. Two test-applications in the Netherlands and a reflection on the way forward. Transport Policy, 12(3), 207-220.

Behrsin, I., \& Benner, C. (2017). Contested spaces and subjectivities of transit: Political ecology of a bus rapid transit development in Oakland, California. Journal of Transport Geography, 61, 95-103.

Bhat, C. R., Handy, S., Kockelman, K., Mahmassani, H. S., Chen, Q., \& Weston, L. (2000). Accessibility measures: formulation considerations and current applications. Work, 7, 4938-2.

Bills, T., Sall, E., \& Walker, J. (2012). Activity-based travel models and transportation equity analysis: Research directions and exploration of model performance. Transportation Research Record: Journal of the Transportation Research Board, (2320), 18-27.

Bills, T. S., \& Walker, J. L. (2017). Looking beyond the mean for equity analysis: Examining distributional impacts of transportation improvements. Transport Policy, 54, 61-69.

Blumenberg, E., \& Ong, P. (2001). Cars, buses, and jobs: welfare participants and employment access in Los Angeles. Transportation Research Record: Journal of the Transportation Research Board, (1756), 22-31.

Bocarejo, J. P., \& Oviedo, D. R. (2012). Transport accessibility and social inequities: a tool for identification of mobility needs and evaluation of transport investments. Journal of Transport Geography, 24, 142-154.

Bullard, R. D. (1994). Overcoming racism in environmental decisionmaking. Environment: Science and Policy for Sustainable Development, 36(4), 10-44.

Bullard, R. D., \& Johnson, G. S. (1997). Just transportation: dismantling and class barriers to mobility. New Society.

Bullard, R. D., Johnson, G. S., \& Torres, A. O. (Eds.) (2004). Highway robbery: Transportation racism \& new routes to equity. South End Press.

Burchardt, T., Le Grand, J., \& Piachaud, D. (1999). Social exclusion in Britain 1991-1995. Social Policy \& Administration, 33(3), 227-244.

Bureau, B., \& Glachant, M. (2011). Distributional effects of public transport policies in the Paris Region. Transport Policy, 18(5), 745-754.

Ceriani, L., \& Verme, P. (2012). The origins of the Gini index: extracts from Variabilità e Mutabilità (1912) by Corrado Gini. The Journal of Economic Inequality, 10(3), 421-443.

Chen, N., \& Akar, G. (2016). How do socio-demographics and built environment affect individual accessibility based on activity space? Evidence from Greater Cleveland, Ohio. Journal of Transport and Land Use, 10(1), 477-503.

Clark, L. P., Millet, D. B., \& Marshall, J. D. (2014). National Patterns in Environmental Injustice and Inequality: Outdoor NO2 Air Pollution in the United States. PLOS ONE, 9(4), e94431.

Currie, G., \& Delbosc, A. (2010). Modelling the social and psychological impacts of transport disadvantage. Transportation, 37(6), 953-966.

Delbosc, A., \& Currie, G. (2011). Using Lorenz curves to assess public transport equity. Journal of Transport Geography, 19(6), 1252-1259.

Dumas, R. A. (2015). Analyzing transit equity using automatically collected data (Doctoral dissertation, Massachusetts Institute of Technology). 
El-Geneidy, A. M., \& Levinson, D. M. (2006). Access to destinations: Development of accessibility measures. Retrieved from http://conservancy.umn.edu/handle/11299/638

El-Geneidy, A., Levinson, D., Diab, E., Boisjoly, G., Verbich, D., \& Loong, C. (2016). The cost of equity: Assessing transit accessibility and social disparity using total travel cost. Transportation Research Part A: Policy and Practice, 91, 302-316.

Fan, Y., Guthrie, A., \& Levinson, D. (2010). Impact of Light Rail Implementation on Labor Market Accessibility: A Transportation Equity Perspective. Journal of Transport and Land Use, 5(3), 28-39.

Feng, T., \& Zhang, J. (2014). Multicriteria evaluation on accessibility-based transportation equity in road network design problem. Journal of Advanced Transportation, 48(6), 526-541.

Foth, N., Manaugh, K., \& El-Geneidy, A. M. (2013). Towards equitable transit: examining transit accessibility and social need in Toronto, Canada, 1996-2006. Journal of Transport Geography, 29, 1-10.

Franklin, J. P. (2005). A non-parametric analysis of welfare redistribution: The case of Stockholm's congestion pricing trial. Submitted to Transportation Research $A$.

Geurs, K. T., Krizek, K. J., \& Reggiani, A. (2012). Accessibility analysis and transport planning: Challenges for Europe and North America. Edward Elgar Publishing.

Geurs, K. T., \& Ritsema van Eck, J. R. (2003). Accessibility evaluation of land-use scenarios: the impact of job competition land-use and infrastructure developments for the Netherlands. Environment and Planning B, 30(1), 69-87.

Geurs, K. T., \& van Wee, B. (2004). Accessibility evaluation of land-use and transport strategies: review and research directions. Journal of Transport Geography, 12(2), 127-140.

Glaeser, E. L., Kahn, M. E., \& Rappaport, J. (2008). Why do the poor live in cities? The role of public transportation. Journal of Urban Economics, 63(1), 1-24.

Golub, A., Marcantonio, R. A., \& Sanchez, T. W. (2013). Race, space, and struggles for mobility: transportation impacts on African Americans in Oakland and the East Bay. Urban Geography, 34(5), 699-728.

Golub, A., \& Martens, K. (2014). Using principles of justice to assess the modal equity of regional transportation plans. Journal of Transport Geography, 41, 10-20.

Grengs, J. (2001). Does public transit counteract the segregation of carless households? Measuring spatial patterns of accessibility. Transportation Research Record: Journal of the Transportation Research Board, (1753), 3-10.

Grengs, J. (2002). Community-based planning as a source of political change: The transit equity movement of Los Angeles' Bus Riders Union. Journal of the American Planning Association, 68(2), 165178.

Grengs, J. (2010). Job accessibility and the modal mismatch in Detroit. Journal of Transport Geography, $18(1), 42-54$.

Grengs, J. (2012). Equity and the social distribution of job accessibility in Detroit. Environment and Planning B: Planning and Design, 39(5), 785-800.

Handy, S. L. (2002). Accessibility-vs. mobility-enhancing strategies for addressing automobile dependence in the US. Institute of Transportation Studies.

Hansen, W. G. (1959). How accessibility shapes land use. Journal of the American Institute of Planners, 25(2), 73-76.

Hess, D. B. (2005). Access to employment for adults in poverty in the Buffalo-Niagara region. Urban Studies, 42(7), 1177-1200.

Hickey, R., Lu, A., \& Reddy, A. (2010). Using quantitative methods in equity and demographic analysis to inform transit fare restructuring decisions. Transportation Research Record: Journal of the Transportation Research Board, (2144), 80-92. 
Hu, L. (2015). Job accessibility of the poor in Los Angeles. Journal of American Planning Association, 81(1), 30-45.

Kain, J.F. (1968). Housing segregation, Negro employment, and metropolitan decentralization. The Quarterly Journal of Economics, 82(2), 175-197.

Karner, A. (2016). Planning for transportation equity in small regions: Towards meaningful performance assessment. Transport policy, 52, 46-54.

Karner, A., \& Golub, A. (2015). Comparison of Two Common Approaches to Public Transit Service Equity Evaluation. Transportation Research Record: Journal of the Transportation Research Board, (2531), 170-179.

Karner, A., \& Niemeier, D. (2013). Civil rights guidance and equity analysis methods for regional transportation plans: a critical review of literature and practice. Journal of Transport Geography, 33, 126-134.

Kenyon, S., Lyons, G., \& Rafferty, J. (2002). Transport and social exclusion: investigating the possibility of promoting inclusion through virtual mobility. Journal of Transport Geography, 10(3), 207-219.

Linneker, B. J., \& Spence, N. A. (1992). Accessibility measures compared in an analysis of the impact of the M25 London Orbital Motorway on Britain. Environment and Planning A, 24(8), 1137-1154.

Litman, T. (2002). Evaluating transportation equity. World Transport Policy \& Practice, 8(2), 50-65.

Litman, T. (2016). Evaluating Transportation Equity Guidance For Incorporating Distributional Impacts in Transportation Planning. Victoria Transport Policy Institute.

Manaugh, K., Badami, M. G., \& El-Geneidy, A. M. (2015). Integrating social equity into urban transportation planning: A critical evaluation of equity objectives and measures in transportation plans in North America. Transport Policy, 37, 167-176.

Martens, C. (2006). Basing transport planning on principles of social justice. Retrieved from http://repository.ubn.ru.nl/handle/2066/45509

Martens, K. (2012). Justice in transport as justice in accessibility: applying Walzer's 'Spheres of Justice'to the transport sector. Transportation, 39(6), 1035-1053.

Martens, K. (2016). Transport justice: Designing fair transportation systems. Routledge.

Martens, K., Golub, A., \& Robinson, G. (2012). A justice-theoretic approach to the distribution of transportation benefits: Implications for transportation planning practice in the United States. Transportation Research Part A: Policy and Practice, 46(4), 684-695.

Merlin, L. A. (2016). A portrait of accessibility change for four US metropolitan areas. Journal of Transport and Land Use, 10(1), 309-336.

Mihyeon Jeon, C., \& Amekudzi, A. (2005). Addressing sustainability in transportation systems: definitions, indicators, and metrics. Journal of infrastructure systems, 11(1), 31-50.

MTC (2009). Change in Motion: Transportation 2035 Plan for the San Francisco Bay Area FINAL. Metropolitan Transportation Commission. Oakland, CA

Owen, A., \& Levinson, D. (2014). Access Across America: Transit 2014. Retrieved from http://conservancy.umn.edu/handle/11299/168102

Pastor, M., Sadd, J., \& Hipp, J. (2001). Which came first? Toxic facilities, minority move-in, and environmental justice. Journal of urban affairs, 23(1), 1-21.

Pereira, R. H. M., Banister, D., Schwanen, T., \& Wessel, N. (2017). Distributional effects of transport policies on inequalities in access to opportunities in Rio de Janeiro. Retrieved from osf.io/preprints/ socarxiv/cghx2

Ramjerdi, F. (2006). Equity measures and their performance in transportation. Transportation Research Record: Journal of the Transportation Research Board, (1983), 67-74.

Rose, M.H. \& Mohl, R.A. (2012). Interstate: Highway Politics and Policy Since 1939. University of Tennessee Press, Knoxville, TN. 
Sanchez, T. W., Stolz, R., \& Ma, J. S. (2003). Moving to Equity: Addressing Inequitable Effects of Transportation Policies on Minorities. Cambridge, MA: The Civil Rights Project at Harvard University.

Shen, Q. (1998). Location characteristics of inner-city neighborhoods and employment accessibility of low-wage workers. Environment and Planning B: Planning and Design, 25(3), 345-365.

Taylor, B.D., Ong, P.M. (1995). Spatial mismatch or automobile mismatch? An examination of race, residence and commuting in US metropolitan areas. Urban Studies, 32(9), 1453-1473.

USDOT (2012). About Us. Retrieved from https://www.transportation.gov/mission/about-us

USDOT Office of the Secretary (2012) Updated environmental justice order 5610.2(a). Fed. Regist. 77, 27534-27537.

van Wee, B., \& Geurs, K. (2011). Discussing equity and social exclusion in accessibility evaluations. European Journal of Transport and Infrastructure Research, 11(4), 350-367.

Walker, J. (2008). Purpose-driven public transport: creating a clear conversation about public transport goals. Journal of Transport Geography, 16(6), 436-442.

Weibull, J. W. (1980). On the numerical measurement of accessibility. Environment and Planning A, 12(1), 53-67.

Welch, T. F. (2013). Equity in transport: The distribution of transit access and connectivity among affordable housing units. Transport Policy, 30, 283-293.

Welch, T.F., Mishra, S. (2013). A measure of equity for public transit connectivity. Journal of Transport Geography, 33, 29-41.

Wells, K., Thill, J.-C. (2012). Do transit-dependent neighborhoods receive inferior bus access? A neighborhood analysis in four U.S. cities. Journal of Urban Affairs, 34(1), 43-63.

Whitt, J. A. (2014). Urban elites and mass transportation: The dialectics of power. Princeton University Press.

Witter, R. (2010). Public urban transport, travel behaviour and social exclusion-the case of Santiago de Chile. In XII World Conference on Transportation Research, Lisbon (July).

Zax, J.S., (1990). Race and commutes. Journal of Urban Economics, 28(3), 336-348.

Zhicai, J. U. A. N., Qingyu, L. U. O., Zhongning, F. U., \& Hongfei, J. I. A. (2008). Equity effects of congestion pricing on urban road resources allocation. Journal of Transportation Systems Engineering and Information Technology, 8(1), 74-79.

\section{Supporting material}

Tables S1-S21 are available online at https:/www.jtlu.org/index.php/jtlu/article/view/1370. 